\title{
Motivações e desafios para a implementação da gestão integrada de recursos hídricos em federações: os casos brasileiro e suíço
}

\author{
Motivations and challenges to implement integrated water \\ resources management in federations: Brazilian and Swiss \\ cases
}

Graziele Muniz Miranda ${ }^{1}$

${ }^{1}$ Instituto Federal de São Paulo, Boituva, SP, Brasil. E-mail: gmunizmiranda@gmail.com

\begin{abstract}
Como citar: Miranda, G. M. (2020). Motivações e desafios para a implementação da gestão integrada de recursos hídricos em federações:
\end{abstract} os casos brasileiro e suíço. Revista de Gestão de Água da América Latina, 17, e6. https://doi.org/10.21168/rega.v17e6

RESUMO: 0 conceito de gestão integrada de recursos hídricos (GIRH) é internacionalmente considerado a forma mais sustentável de gerir os recursos hídricos. Visando sua implementação, governos internacionais modificam seu quadro legal e institucional para aumentar a participação local e implementar ferramentas de gestão de águas no perímetro da bacia hidrográfica. Tais mudanças podem representar alguns desafios para federações, pois a divisão de poderes entre os níveis nacional e subnacional é complexa. Este artigo possui o objetivo de discutir o desenvolvimento do modelo de GIRH divulgado internacionalmente em federações, analisando dois casos diferenciados de países federais: Brasil e Suíça. Por meio de pesquisa bibliográfica, busca-se enfatizar as diferenças entre tais federações e relacioná-las com as características de seus sistemas de gestão de recursos hídricos. 0 estudo revela que há menos interesse em um modelo de GIRH de forma sistemática no país quando os governos subnacionais possuem forte autonomia, estabilidade política e econômica (como a Suíça) em comparação a federações mais centralizadas (como o Brasil).

Palavras-chave: Federalismo; Integração; Bacia Hidrográfica; Participação.

ABSTRACT: The concept of integrated water resources management (IWRM) is internationally considered as the most sustainable way to manage water. Thus, international governments have modified their legal and institutional framework to enhance local participation and implement water management tools in the watershed perimeter. Those changes can represent some challenges in federations since the sharing of power between national and subnational levels is very complex. This paper aims to discuss the development of the IWRM model spread internationally in federations, analyzing two different federal countries: Brazil and Switzerland. Through bibliographic research, we emphasize the differences between such federations and their water resources management models. The study reveals that there is less interest in a systematic model of IWRM when subnational levels have strong autonomy, economic and political stability (as the Swiss case), unlike more centralized federations (as the Brazilian case).

Keywords: Federalism; Integration; Watershed; Participation.

\section{INTRODUÇÃO}

Nas últimas décadas, a comunidade internacional tem percebido que os problemas hídricos envolvem dimensões e setores múltiplos, compreendendo igualmente uma diversidade de interesses, agendas e causas (Biswas, 2004). Tal complexidade evidencia as limitações de uma gestão setorial e centralizada (Global Water Partnership, 2000; Remon, 2018) e requer uma coordenação incluindo os múltiplos atores durante o processo de tomada de decisões.

Nesse sentido, o conceito de gestão integrada de recursos hídricos (GIRH) surge para promover o desenvolvimento coordenado e a gestão das águas, solos e recursos relacionados para maximizar o bem-estar econômico e social sem comprometer a sustentabilidade dos ecossistemas vitais (Global Water Partnership, 2000). Desde a década de 1990, a GIRH vem sendo divulgada mundialmente por

Recebido: Março 18, 2020 - Revisado: Maio 09, 2020 - Aceito: Maio 30, 2020 
inúmeras instituições internacionais, especialmente a Associação Mundial pela Água (Global Water Partnership - GWP) e o Banco Mundial. Tal conceito está vinculado a alguns princípios gerais durante a gestão de águas: bacia hidrográfica como unidade territorial, participação dos atores, mecanismos de financiamento, monitoramento e sistema de banco de dados; todos eles previstos em legislação específica e executados por instituições de bacias (Global Water Partnership, 2000; Milano et al., 2018; Miranda; 2017).

Desde então, legislações nacionais e estruturas institucionais têm sido modificadas para adotar o conceito. Em alguns países unitários, como a França, instituições de bacia foram criadas no país todo. Entretanto, em federações, a criação de instituições de bacia representa uma estrutura de gestão adicional as já existentes. Isso ocorre pelo fato de haver divisão de poderes nas federações e relativa autonomia entre os níveis nacional e subnacional de acordo com uma constituição federal. Em federações descentralizadas, como é o caso da Suíça, o processo de tomada de decisões tende a ser mais complexo porque cada nível subnacional possui forte autonomia para decidir e executar políticas públicas. Assim, os exemplos de gestão de águas são mormente heterogêneos em tais países. Em federações mais centralizadas, há uma modesta devolução de poder aos governos subnacionais e, dessa forma, podem se assemelhar a países unitários.

Apenas recentemente pesquisadores têm mostrado interesse pela relação entre o federalismo e a questão hídrica. Garrick \& O’Donnell (2018) compararam mercados de água associados a reformas institucionais em federações; De Stefano \& Garrick (2018) e Empinotti et al. (2018) estudaram os desafios envolvendo a governança de águas em alguns países federais. Entretanto, nenhum deles focou nas motivações e desafios durante a implementação do conceito de GIRH em países federais.

Pelo fato de existirem diferentes tipos de federalismos, o desenvolvimento da gestão integrada de recursos hídricos em federações é igualmente diverso. Por isso é importante compreender por que a institucionalização de um modelo internacional de GIRH pode ser desejado por algumas federações e, por outro lado, ser menos esperado em outras. Desse modo, este artigo propõe, por meio de pesquisa bibliográfica, discutir o desenvolvimento do modelo de GIRH em federações. A primeira parte apresenta uma visão geral de sua aplicação em federações da Europa e América. A segunda parte descreve a evolução da GIRH no Brasil, durante o período de redemocratização do país. Em seguida, ilustra-se a relação entre o tipo de federalismo suíço e sua diversidade de modelos de gestão de águas. Por fim, discute-se os principais fatores que influenciam o desenvolvimento da GIRH e sua implementação em países federais.

\section{FEDERALISMO E GESTÃO INTEGRADA DE RECURSOS HÍDRICOS}

Federalismo abrange a compreensão da diversidade na unidade (Croisat, 2010), ainda que nem todos os países diversos sejam federais e nem todas as federações sejam diversas (Soares \& Machado, 2018). Mesmo que uma definição universal de federalismo não exista, autores concordam que países federais possuem particularidades e princípios fundamentais (Croisat, 2010; Bizberg, 2015; SaintOuen, 2005; Riker, 2017). Tais princípios estão relacionados à existência de níveis subnacionais, uma constituição federal que reconheça determinados poderes legais e fiscais, relativa autonomia e divisão de poderes durante o processo de tomada de decisões. Além disso, pode existir um organismo ou procedimento legal para gerir conflitos entre os níveis nacional e subnacional.

Países federais podem ser formados a partir de um processo de descentralização de competências dos níveis subnacionais com a divisão de um governo unitário, como o Brasil depois do período monárquico, ou por um processo de centralização de competências com a aliança de governos independentes, como a Suíça. Desse modo, pode-se compreender que o nível de descentralização das federações varia de acordo com a transferência de poderes para os níveis subnacionais em relação a competências legais, jurídicas, regras fiscais e implementação de políticas públicas.

Alguns autores fazem distinção entre federalismo dual descentralizado, cooperativo descentralizado e centralizado (Briant \& Briant, 2009; Liziero \& Carvalho, 2018; Trein \& Braun, 2016). No primeiro caso, há uma clara separação de competências entre os níveis nacional e as entidades constituintes (governos subnacionais), como por exemplo os Estados Unidos. 0 segundo indica que há uma cooperação entre os níveis governamentais em diferentes áreas, como a Suíça e a Alemanha. Nas federações descentralizadas ocorre uma forte transferência de autoridade e responsabilidade do governo federal para os governos subnacionais. Por outro lado, em federações mais centralizadas (como a Venezuela), o governo nacional controla a maioria dos assuntos relacionados às regras fiscais e políticas públicas (às vezes igualmente assuntos legislativos) (Figura 1). 


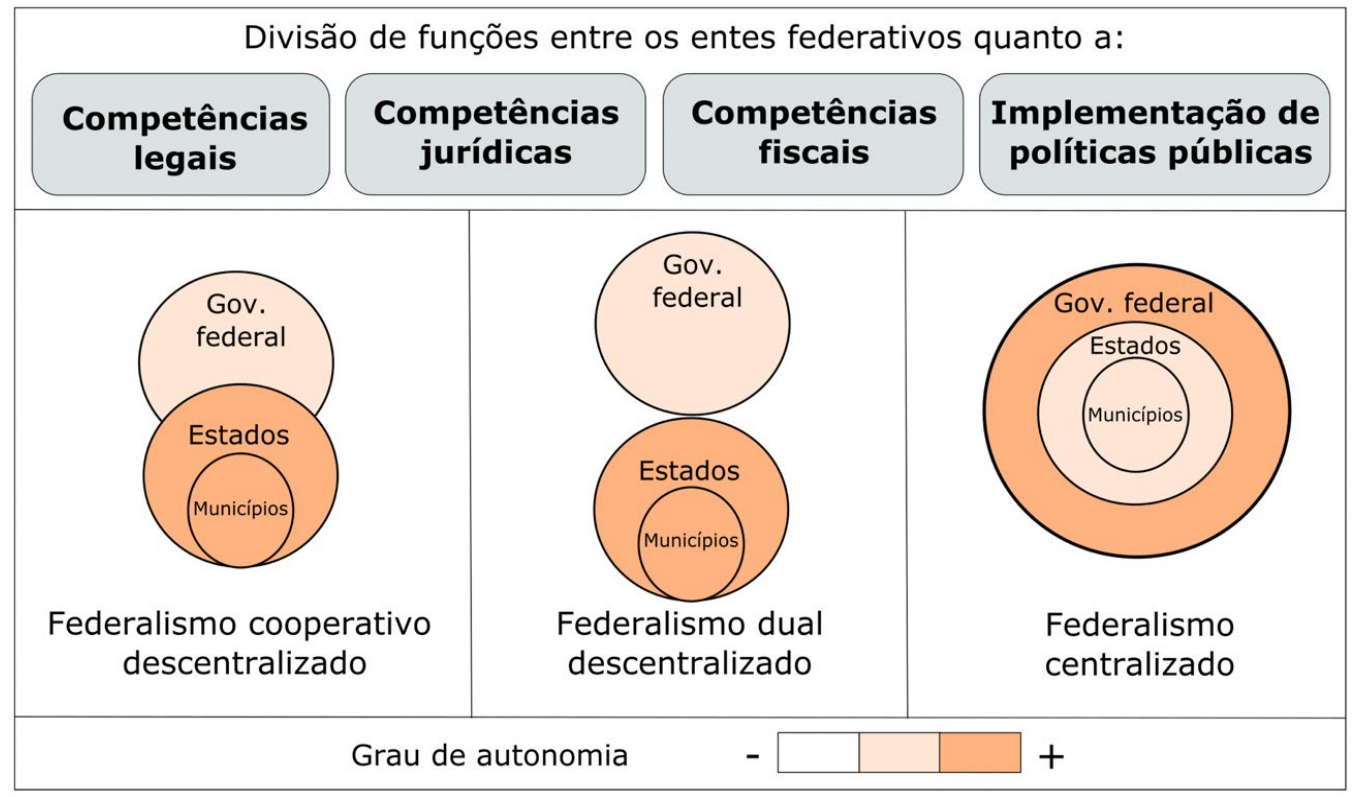

Figura 1: Principais tipos de federalismos existentes. Fonte: Autor.

Com o passar do tempo, federações podem evoluir linearmente para uma maior centralização ou descentralização. Entretanto, em alguns casos este processo pode não ser linear de acordo com instabilidades políticas e econômicas durante o processo histórico. Para alguns autores (Bizberg, 2015; Posner, 2014; Robertson, 2018), federalismo existe apenas em democracias estáveis, pois há mecanismos para garantir uma não total centralização.

o federalismo latino americano, representado pela Argentina, Brasil, México e Venezuela, apresenta um caso interessante de não-linearidade. Todos esses países passaram por governos autoritários no passado recente ou atualmente (como a Venezuela). Assim, o fortalecimento do federalismo latino americano está fortemente ligado ao aumento da democracia (Bizberg, 2015). Em outras palavras, o período pós-ditadura em tais países relaciona-se ao desejo de participação pública e descentralização dos poderes em diferentes setores, incluindo a gestão de águas, bem como uma desconfiança em relação aos governos centrais (Trillo, 2015). Em alguns casos, a privatização do sistema de água e esgoto ocorreu sob o pretexto de descentralização, especialmente no caso mexicano (Espinosa, 2015).

Ao mesmo tempo que antigas ditaduras foram dissolvidas na América Latina, o conceito de gestão integrada de recursos hídricos (GIRH) emerge internacionalmente como a forma mais sustentável de gerir os múltiplos usos da água (integração horizontal) e os níveis institucionais (integração vertical) (Reynard, 2000). Apesar das experiências de gestão de águas envolvendo múltiplos setores por bacia hidrográfica existir desde ao menos 100 anos (White, 1998), sua aplicação atual possui características normativas de acordo com relatórios internacionais (Global Water Partnership, 2005; World Bank, 2000). Além disso, evoca o estabelecimento de instituições no perímetro da bacia hidrográfica, a descentralização e a participação de múltiplos atores durante o processo de tomada de decisões.

Existiram alguns casos relativamente antigos de gestão por bacia hidrográfica na América Latina, como o chileno, em 1952, e o mexicano, em 1946 (Miranda, 2017), objetivando sobretudo o desenvolvimento energético. Mas desde a década de 1990, o cenário pós-ditatorial no continente representou um terreno fértil para mudanças legais e institucionais para adotar o conceito normativo internacional de GIRH. Desde então, todos os países federais (e a maioria dos unitários) da região criaram instituições de bacia e agências nacionais de água. Porém, o modelo internacional estabelecido na região não seguiu práticas homogêneas. Existem variações na implementação do sistema de gestão de águas de acordo com a dominialidade das águas e a divisão de competências. Na Venezuela e no México, federações muito centralizadas, o governo federal é o responsável pelo setor hídrico e em ambos os casos a autoridade nacional decide os limites geográficos para a criação de organismos de bacia no país todo (Organisation for Economic Co-operation and Development, 2012; Villada-Canela et al., 2019). 
No caso argentino, o governo federal tentou, sem sucesso, instituir a criação de organismos de bacia de acordo com a lei sobre o regime de gestão de águas $n^{\circ} 25688 / 2002$ segundo os interesses do Banco Mundial (World Bank, 2000). Tal lei sofreu duras críticas por parte das províncias por se tratar de uma política centralizadora, que não considera que as províncias possuem competência sobre seus recursos hídricos (Organisation for Economic Co-operation and Development, 2019; Rovere, 2006). As jurisdições no setor de gestão de águas mantêm-se nos níveis subnacionais (províncias) e organismos interprovinciais são criados desde a década de 1960 apenas com propósitos específicos, como obras hidráulicas. 0 poder de tomada de decisões e planejamento permanece assim em mãos das províncias, pois a dominialidade das águas pertence a elas. 0 governo federal não possui poder de arbitragem, mas age como facilitador técnico ou financeiro (Cenicacelaya, 2014).

Em relação às federações europeias, apesar do seu relativo pequeno tamanho, estas apresentam características multilinguísticas, variedade nos sistemas políticos e casos ainda mais heterogêneos de governança de águas, como pode ser visto por exemplo na Alemanha, Bélgica, Suíça e Espanha ${ }^{1}$. Existe uma fraca influência do modelo internacional de GIRH em tais países. Porém, com a Diretiva Quadro da Água (Diretiva 2000/60/CE do Parlamento Europeu e do Conselho, de 23 de outubro de 2000), existem esforços para uma padronização da gestão de águas.

0 primeiro exemplo de gestão de águas por bacia hidrográfica é encontrado na Alemanha com a criação de duas instituições (Ruhrverband e Ruhrtalsperrenverein) responsáveis pela gestão de águas da bacia do Ruhr, já em 1913 (Petry \& Dombrowsky, 2007). Tais instituições buscavam unir os atores (usuários, comunidades locais e companhias) para realizar uma gestão participativa para discutir políticas de água e aplicar instrumentos econômicos por meio da contribuição financeira dos membros para financiar investimentos na bacia. Tal modelo foi inovador para a época e influenciou posteriormente experiências internacionais, como a francesa (Barraque, 2007) e a brasileira. Atualmente, na Alemanha a gestão de águas é decidida de forma bastante pragmática pelos Länder (governo subnacional) e não existe interesse em implementar instituições de bacias de forma sistemática por todo o país, como foi o caso na França e no Brasil (Laigneau et al., 2018).

A Espanha apresenta igualmente uma antiga experiência em gestão por bacia de acordo com decretos reais referentes à criação de confederações hidrográficas (confederaciones sindicales hidrográficas). Tais organismos autônomos de direito público foram criados durante um governo centralizador, visando a descentralização de políticas de água por bacia (Buchs, 2010), mas com uma visão setorial de gestão de águas (energia hidráulica). Sua criação não foi sistemática por todo o país, ocorrendo primeiro em regiões onde a falta de água é mais flagrante: Ebro, em 1926, Segura em 1926, Duero em 1927, Guadalquivir em 1927, Júcar em 1934, Guadiana e Tajo, em 1953 (Miranda, 2017); enquanto no norte, mais montanhoso e úmido, confederações começaram a ser criadas em 1961. Com a adoção da lei atual de águas 29/1985 no período democrático pós-ditadura, o Estado e as confederações passam a gerir conjuntamente as bacias que vão além dos limites das comunidades autônomas (governo subnacional) espanholas (bacias intercomunais). Nos casos em que as bacias se restringem apenas a uma comunidade autônoma (bacias intracomunais), o poder é mantido em tais comunidades autônomas. Entretanto, a integração das competências é bastante complexa e motiva tensões e conflitos entre a administração central e as comunidades autônomas (Palacios, 2012).

A Bélgica mudou igualmente de um governo unitário, em que o governo nacional controlava três companhias de água e esgoto baseadas no território de bacias hidrográficas, para um sistema federal. A gestão de águas passou a ser fragmentada e diferenciada em três governos regionais (Visscher \& Laborderie, 2013), que possuem grande liberdade para legislar e decidir sobre políticas de águas (exceto sobre águas marítimas). Além disso, não existe lei nacional sobre águas, apenas leis regionais, evidenciando a forte autonomia e heterogeneidade de modelos de gestão de águas no país.

Estados Unidos e Canadá possuem experiências antigas de gestão de águas. Em âmbito transfronteiriço, a cooperação entre ambos data de 1909 (Pearse \& Quinn, 2013). Nos Estados Unidos, um organismo de gestão por bacia hidrográfica passou a existir em 1917, mas antes disso, em 1907, uma comissão formada pelo governo considerou a região do Mississipi e Grandes lagos para estudar vias navegáveis interiores para o sistema de transporte. Desde 1933 uma abordagem integrada de bacia é desenvolvida a partir do exemplo da Agência do Vale do Tennessee (Tennessee Valle Authority - TVA). Assim como o exemplo alemão, o modelo pioneiro de gestão integrada de recursos hídricos nos Estados Unidos influenciou inúmeros casos internacionais, ainda que os Estados Unidos não tenham adotado o exemplo da TVA no país todo até a atualidade (Sandoval-Solis, 2019). Pelo contrário, os

${ }^{1}$ De acordo com as características do Sistema Político Espanhol, autores citam o país como um federalismo imperfeito (Moreno, 1997), federalismo incompleto (Grau, 2000) ou governo unitário ultra-federal (Bieusses, 2008). 
estados do país possuem exemplos bastante diversificados de gestão de águas e não seguem um modelo único de GIRH.

No Canadá, o primeiro exemplo de gestão integrada de recursos hídricos por bacia hidrográfica data de 1940 na província de Ontário, e assim como no país vizinho, tal exemplo não foi adotado sistematicamente no país (Schrubsole et al., 2016). Em ambos os casos o governo federal possui um papel de incentivador da abordagem integrada, pois estados (nos Estados Unidos) e províncias (no Canadá) possuem exclusividade na maior parte das competências relacionadas à gestão de águas no país. Assim, os modelos de gestão de águas são muito numerosos e variam de acordo com cada realidade.

Desse modo, os primeiros exemplos de gestão de águas compreendendo múltiplos usos por bacia hidrográfica em países federais (Alemanha, Estados Unidos e Canadá), na primeira metade do século passado, não foi acompanhada por sua sistematização nesses mesmos países. Nesses casos, os motivos foram principalmente o desenvolvimento de uma região específica, uma melhor distribuição dos recursos hídricos ou o financiamento para projetos de recuperação e/ou obras de engenharia.

\section{OS EXEMPLOS BRASILEIRO E SUÍÇO DE GESTÃO DE ÁGUAS}

Ainda que o Brasil e a Suíça possuam algumas similaridades referentes a características multiculturais e relativa abundância de águas, trata-se de países muito diferentes de acordo com as características do federalismo (forte autonomia dos governos regionais e locais na Suíça e maior centralidade no Brasil), tamanho (a Suíça representa aproximadamente 0,5\% do tamanho do Brasil) e igualdade social (o coeficiente de Gini brasileiro era 53.3 contra 32.3 da Suíça em 2017) (World Bank, 2019).

O Quadro 1 resume as principais características e diferenças relacionadas à gestão de águas no Brasil e na Suíça.

Quadro 1: Características da gestão de recursos hídricos no Brasil e na Suíça.

\begin{tabular}{|c|c|c|}
\hline Critérios & Brasil & Suíça \\
\hline Sistema de governo & Federal. & Federal. \\
\hline Características regionais & $\begin{array}{c}\text { Heterogeneidade em âmbito } \\
\text { econômico, demográfico, cultural } \\
\text { e ambiental. }\end{array}$ & Diversidade multilinguística. \\
\hline GIRH na lei? & $\begin{array}{c}\text { Sim, na lei federal e nas leis } \\
\text { estaduais. Tais legislações são } \\
\text { similares. }\end{array}$ & $\begin{array}{c}\text { Não em âmbito federal. Certos } \\
\text { cantões começam a incorporar o } \\
\text { conceito em sua legislação. Leis e } \\
\text { experiências são muito } \\
\text { heterogêneas. }\end{array}$ \\
\hline Estímulo e interesse pela GIRH & $\begin{array}{c}\text { Sim. Nos níveis federal, estadual e } \\
\text { por bacia hidrográfica. }\end{array}$ & $\begin{array}{c}\text { Sim. Em âmbito federal por meio } \\
\text { de relatórios e guias. Interesse } \\
\text { variável em cada cantão. }\end{array}$ \\
\hline Unidade territorial de gestão & Bacia hidrográfica. & Político-administrativa. \\
\hline
\end{tabular}

\section{O EXEMPLO BRASILEIRO DE GESTÃO DE ÁGUAS}

O histórico da gestão de águas no Brasil tem passado por diversas transformações diretamente relacionadas às mudanças no tipo de federalismo do país. A criação de um sistema federal visou a obtenção de autonomia regional em um país formado a partir de um sistema autoritário e unitário em torno de um Estado monárquico, logo após sua independência. Desse modo, o federalismo brasileiro surge não por conta da vontade voluntária de entidades independentes, mas por decisão do governo central. Posteriormente, o país passa por fases consecutivas de maior e menor centralização do poder.

Com a Constituição Federal de 1988, os municípios passam a poder legislar e, além disso, são responsáveis pelo saneamento e ordenamento do território. No entanto, na prática, o atual modelo federalista brasileiro combina um poder de decisão centralizado com uma execução descentralizada de políticas públicas (Arretche, 2015; Carmo, 2019; Empinotti et al., 2018). Em outras palavras, mesmo que tentativas tenham sido feitas para dar mais poder ao governo local, estados e municípios devem executar políticas públicas decididas pelo governo federal. 
No setor de recursos hídricos, a lei de águas 9433/1997 estabelece a criação de instituições de bacias hidrográficas (comitês e agências) visando maior descentralização e participação do poder de decisão e a implementação de ferramentas de gestão relacionadas a aspectos financeiros, de planejamento e monitoramento da bacia. 0 modelo foi inspirado principalmente na experiência francesa (Laigneau et al., 2018) e adaptado a um país federal. Nos anos seguintes, o Banco Mundial edita uma série de relatórios contendo as instruções para a aplicação da política hídrica nacional (Banco Mundial, 2003; Scantimburgo, 2013; World Bank, 1999).

Um dos maiores desafios para colocar em prática a gestão integrada por bacias hidrográficas no Brasil está relacionado à dominialidade das águas, pois os rios podem pertencer ao governo federal (se fluírem por mais de um estado) ou estadual (se permanecerem em um mesmo estado). Por outro lado, a gestão de águas deve ser realizada por bacias hidrográficas. Esta repartição foi decidida visando diminuir a competição histórica dos estados, com vantagem da neutralidade federal. Porém, isso gera várias dificuldades práticas e maior complexidade para o sistema (Gontijo \& Trigo, 2013). As bacias hidrográficas dos rios Piracicaba, Capivari e Jundiaí (PCJ), por exemplo, possuem rios federais e estaduais. Assim, existem três comitês para executar o gerenciamento de águas em uma mesma bacia. Todas as decisões tomadas devem ser decididas pelos três comitês. Se existem algumas diferenças entre as regras de Minas Gerais e São Paulo (como por exemplo em relação ao instrumento de cobrança), o processo torna-se mais lento (Miranda, 2017).

Para Libânio (2014), o país obteve maiores avanços nas últimas décadas em relação aos princípios de participação e descentralização do que o princípio de integração, ao menos em termos conceituais e institucionais. A esse respeito, a lei estabelece que diferentes setores, como ordenamento territorial, gestão ambiental, qualidade e quantidade de águas, questões socioeconômicas, bem como planejamento regional, estadual e nacional devem ser integrados à gestão de recursos hídricos, sem definir, porém, o significado do termo integração. Diversos atores relacionados à gestão de águas nos níveis federal, estadual e de bacia hidrográfica tendem a destacar a importância da participação local durante o processo de tomada de decisão quando questionados sobre o conceito de integração (Miranda, 2017). Assim, a GIRH no Brasil está estritamente relacionada à participação e à descentralização como forma de democratizar a gestão da água.

Mesmo que bem definido, o sistema legal brasileiro ainda é complexo. Apesar de uma década entre a primeira e a última gestão estadual de águas (1991 a 2002), podemos notar que os mesmos instrumentos e objetivos aparecem nas diferentes legislações de todo o país sem considerar as disparidades regionais. Gontijo \& Trigo (2013) avaliou dez estudos de caso em instituições de bacias hidrográficas, nove no Brasil e uma na França (inspiração para o modelo brasileiro). 0 autor conclui que os instrumentos da política de recursos hídricos vêm sendo implementados de modo semelhante no Brasil todo sem considerar as particularidades locais. Além disso, enfatiza que existe a necessidade de uma maior descentralização decisória.

Outros autores (Libânio, 2018; Empinotti et al., 2018) salientam a fragilidade do modelo participativo brasileiro. Os comitês de bacia possuem pouca habilidade para fazer uso de seus poderes deliberativos e importantes decisões têm sido negligenciadas por autoridades públicas. Tais instâncias de participação são responsáveis pela elaboração do plano de bacia hidrográfica visando a recuperação, proteção e conservação dos recursos hídricos da bacia. Porém, os municípios são incumbidos pela realização de planos direta ou indiretamente relacionados às águas (como plano diretor e plano de saneamento básico) sem serem obrigados a seguir o plano de bacias hidrográficas. Tal realidade debilita a implementação sistemática da gestão integrada no país conforme consta na política nacional de recursos hídricos (Brasil, 1997), que evoca no artigo 3 a necessidade de "articulação da gestão de recursos hídricos com a do uso do solo".

Por outro lado, muitos comitês são incapazes de gerar receita suficiente para apoiar a gestão de águas, aumentando significativamente a dependência financeira no sistema federal e diminuindo a autonomia das organizações subnacionais. De acordo com Empinotti et al. (2018), em regiões onde não existem instituições descentralizadas, tal lacuna é preenchida por decisões federais. Há igualmente grandes esforços (sobretudo financeiros) em elaborar planos e menos em executá-los (Gontijo \& Trigo, 2013; Libânio, 2014).

\section{O EXEMPLO SUÍÇO DE GESTÃo DE ÁGUAS}

Se o interesse em um modelo estruturado de GIRH no Brasil reflete seu federalismo relativamente centralizado, a Suíça possui outras razões para encorajar abordagens variadas de GIRH. O país foi durante cinco séculos uma confederação e desde 1848 é oficialmente uma federação, ainda que 
documentos oficiais e cidadãos mantenham o termo confederação. Diferentemente do Brasil (Arretche, 2015; Empinotti et al., 2018), a Suíça é uma das federações mais descentralizadas e participativas do mundo (Dardanelli, 2010). Segundo o autor, a autonomia do cantão ${ }^{2}$ resulta da sua origem federal (reagrupamento de estados soberanos) e da crença que o poder local reflete o poder dos cidadãos e por isso ele é preferível ao nacional. Assim, a maioria das áreas de competência federal é decidida e executada por cantões. A participação é garantida por instrumentos previstos na Constituição Federal. Referendo obrigatório, referendo facultativo e iniciativa popular, todos encontrados nos níveis federal, cantonal e comunal, garantem a participação do cidadão em caso de alteração na Constituição e em mudanças legislativas em diferentes áreas. Um exemplo é o fato de o país não ser membro da União Europeia, a partir da decisão da população.

Em 1991, foram implementadas leis setoriais da água (Lei Federal de Proteção da Água, Lei Federal de Proteção contra Inundação e Lei Federal de Pesca) (Musy et al., 2014), mas até o momento não há interesse por parte dos governantes em ter uma única lei federal considerando o conceito de GIRH (Buchs, 2018). Por outro lado, os cantões são responsáveis pelo planejamento e gestão dos recursos hídricos e há muitos modelos de gestão de águas no país, reflexo da forte autonomia local e do fato das competências comunais poderem variar de acordo com os cantões.

A abordagem de GIRH na Suíça pode ser entendida a partir da baixa influência de um único modelo internacional, da informalidade do sistema, de uma abordagem por prioridades, de sua heterogeneidade e lento processo de implementação. Como o país não é membro da União Europeia e não é economicamente dependente de instituições internacionais, como o Banco Mundial, há maior flexibilidade na escolha de seu modelo de gestão de águas, de acordo com os interesses locais. Em outras palavras, uma abordagem integrada não é obrigatória, mas estimulada, e os cantões possuem liberdade em escolher seu modelo de gestão.

Desde a última década, a Confederação Suíça incentiva a abordagem de GIRH no país por meio de relatórios e documentos oficiais (Buchs, 2016, 2018; Office Fédéral de L'environnement, 2012, 2013) tentando persuadir os cantões sobre sua importância. De acordo com tais documentos, a abordagem de GIRH deve levar em consideração vários setores hídricos durante o desenvolvimento de um projeto. Diferentemente do modelo internacional de GIRH, o conceito é estimulado com reservas. Justifica-se apenas por projetos específicos que demandem uma real coordenação intersetorial (Aschwanden et al., 2008). Além disso, o perímetro da GIRH não é necessariamente a bacia hidrográfica, assim como a gestão de bacias hidrográficas nem sempre deve incluir múltiplos usos da água. Resumidamente, a abordagem de GIRH na Suíça se concentra mais em metas e menos em formato, já que a GIRH é considerada como uma ferramenta que pode ser usada apenas em caso de grande necessidade de coordenação entre os usos.

Diferentemente da experiência brasileira, os desafios relativos à implementação da GIRH no país estão menos relacionados à descentralização e à participação como direitos democráticos, pois estes já estão mencionados na Constituição. Além disso, alguns atores consideram que uma maior participação pode levar a uma maior burocracia e lentidão no processo de planejamento e gestão (Miranda, 2013, 2017; Utz \& Reynard, 2017).

Os desafios suíços se relacionam à colaboração intercantonal e à dificuldade de mudar a visão de planejamento de uma microgestão (pequenas comunas) para uma visão regional por bacia hidrográfica (Buchs, 2018). Como a estratégia de persuasão é um processo lento, a gestão de águas no país continua sendo principalmente setorial. Assim, apesar dos esforços da Confederação, a gestão de águas ainda é fragmentada em relação à coordenação entre os níveis federal, cantonal e comunal e entre os diferentes usos da água. Isso pode representar custos adicionais e falta de uma visão geral regional. De acordo com projetos financiados pela Fundação Nacional Suíça de Ciências (Swiss National Science Foundation-SNSF) (Balsiger \& Menzel, 2012; Comite de Direction du PNR 61, 2015), a abordagem de gestão integrada de recursos hídricos ainda é incipiente e não existe um modelo ideal, uma vez que cada caso examinado é diferente de acordo com o seu contexto.

Não existe interesse em instituições de bacias hidrográficas em todo o país por quatro razões (Buchs, 2016, 2018; Comite de Direction du PNR 61, 2015; Graefe, 2011; Miranda, 2013, 2017; Milano et al., 2015; Utz \& Reynard, 2017): 1. Os atores regionais e locais (especialmente comunas e cantões) não acreditam que haja crise de água ou grandes conflitos entre o uso da água nas bacias hidrográficas. 2. Os perímetros de uso são muito diferentes de acordo com cada utilização. Por exemplo, é bastante comum ter uma estação de tratamento de água compartilhada por algumas comunas (devido ao seu pequeno tamanho), enquanto os fornecedores de água potável atendem

${ }^{2}$ Os governos subnacionais são os cantões e as comunas. 
outras comunas. Desta forma, seria difícil delimitar um perímetro comum a todos os usos. 3. Municípios temem enfraquecer seu poder de decisão com a criação de um novo órgão. Mesmo que seja apenas representado por governantes, a divisão de competências é vista como complicada. 4. Como a participação é bastante forte no país e os suíços são muito pragmáticos, os atores tendem a pensar que a criação de grupos participativos poderia significar mais horas de discussões e menos de execução. Consideram ainda que poderia ser mais fácil adaptar parcerias setoriais existentes incorporando novos usos ao invés de se criar um novo organismo na área da bacia.

A dominialidade da água no país é igualmente complexa, podendo ser pública (cantonal ou comunal, mas nunca federal), privada ou adquirida. Cada cantão decide se mantém para si as competências em matéria de água ou delega às comunas. De acordo com a Constituição Federal, o Código Civil Suíço e várias leis federais e cantonais (Reynard, 2000), as águas subterrâneas são privadas e ligadas à propriedade da terra (Artigo 704 CC); águas superficiais e glaciares são geralmente cantonais, municipais ou privadas (de acordo com cada cantão). Comum em setores hidráulicos e de irrigação, direitos adquiridos são relativos ao sistema judicial anterior às leis vigentes.

\section{GESTÃO INTEGRADA DE RECURSOS HÍDRICOS EM PAÍSES FEDERAIS}

A implementação da GIRH possui desafios distintos de acordo com o tipo de federalismo (pela maior ou menor autonomia dos governos subnacionais em relação ao governo central), a história política (a existência de uma democracia estável ou, ao contrário, histórico de governos autoritários) e desenvolvimento econômico (maior ou menor dependência de instituições internacionais) (Figura 2).

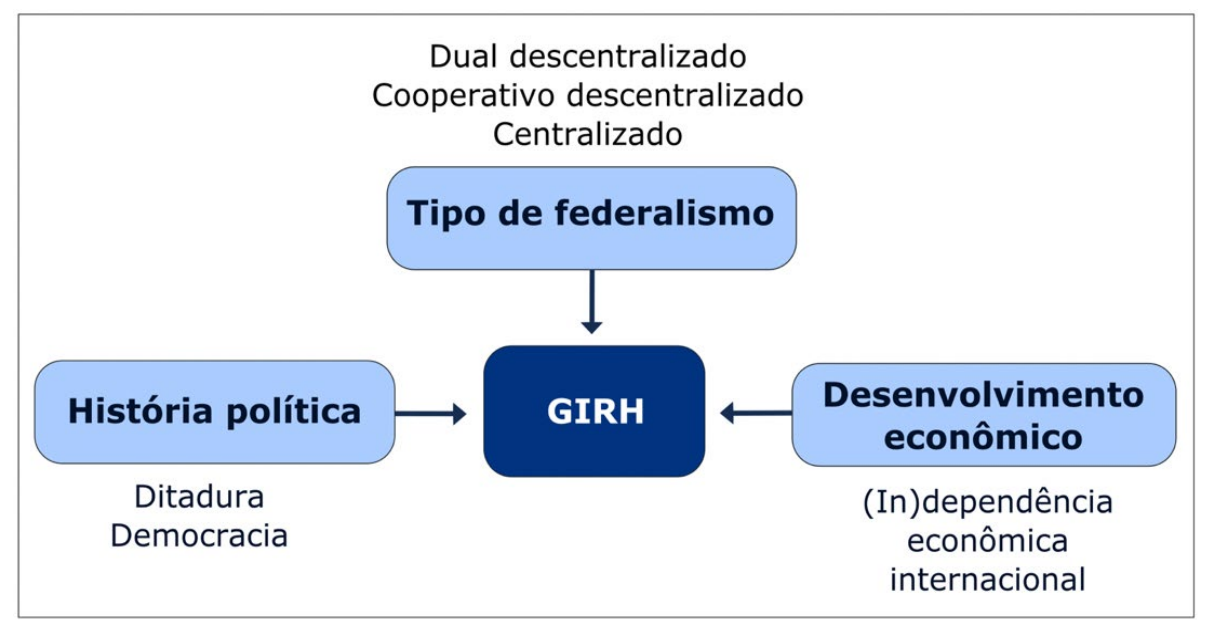

Figura 2: Fatores que afetam a implementação da GIRH em países federais. Fonte: Autor.

A Suíça é uma federação bastante descentralizada, com uma democracia historicamente estável e financeiramente independente se comparada a outros países ou mesmo os da União Europeia. Atualmente possui experiências muito heterogêneas de implementação da GIRH. Isso justifica-se porque (1) os governos locais e regionais possuem maior autonomia em âmbito legal, fiscal e de aplicação de políticas públicas e, consequentemente, as soluções encontradas são diversificadas e (2) existe menor dependência econômica em relação a instituições financeiras internacionais e à influência destas em suas decisões políticas, contrariamente a países emergentes como o Brasil.

O conceito de GIRH vêm sendo promovido no país por persuasão (por parte do nível federal junto aos governos regionais e locais) e por consenso (por atores cantonais e locais). Em outras palavras, o governo federal busca convencer os governos locais de que a gestão integrada pode ser vantajosa e estes escolhem se pretendem mudar seu modo de gestão e como irão proceder.

Em federações historicamente mais centralizadas, como o Brasil, os estados são muito dependentes do governo federal, ainda que determinados poderes estejam garantidos pela constituição. Na prática, as decisões são frequentemente tomadas pelo governo federal e então executadas pelos governos regionais e locais de forma bastante homogênea. Os instrumentos de 
gestão previstos em lei federal, como planos, sistema de informações, etc. existem de modo muito similar em âmbito estadual.

Desse modo, ainda que o conceito normativo de GIRH seja disseminado globalmente, o formato, os objetivos e os motivos para se adotar a abordagem da GIRH diferem-se consideravelmente de uma federação a outra. No Brasil, o conceito está diretamente relacionado à participação e à descentralização devido ao histórico de ditaduras militares. Na Suíça, a participação e a descentralização sempre fizeram parte do federalismo. Destarte, o termo possui múltiplos significados e formatos, representando geralmente uma abordagem por prioridades, mesmo que nem sempre considere os múltiplos usos das águas.

O principal desafio para a aplicação da GIRH no Brasil é a efetiva descentralização e participação. Na prática, os comitês possuem fraco poder decisório (Empinotti et al., 2018). De outro modo, na Suíça, o poder é concentrado localmente em pequenas comunas e há uma deficiência de visão geral (Buchs, 2018). Portanto, seu principal desafio é a regionalização e a coordenação das decisões, que se encontram historicamente dispersas.

Por um lado, o modelo de gestão de águas no Brasil mostra-se mais formal e encorpado, porém falta maior pragmatismo para a aplicação dos instrumentos previstos. Por outro lado, percebe-se grande informalidade no sistema suíço. Entretanto, são mais pragmáticos ao trabalharem por projetos e focarem na realização de objetivos e não na elaboração de múltiplos planos.

\section{CONCLUSÕES}

A GIRH é globalmente mais complexa em sistemas federais se comparados a sistemas unitários, pois federações possuem algumas particularidades, como divisão de competências entre os níveis nacional e regional/local e relativa autonomia dos governos subnacionais de acordo com uma constituição federal. Além disso, o nível regional pode participar do processo de tomada de decisão por meio da existência de câmara dos deputados (câmara baixa) e senado (câmara alta). Desse modo, ainda que federações sejam heterogêneas de acordo com a divisão de poderes (legais, fiscais, jurídicos e de execução das políticas públicas), tais características as distinguem de países unitários.

Este artigo apontou as características principais dos federalismos brasileiro e suíço, relacionando às particularidades de seus sistemas de gestão de recursos hídricos. No Brasil, o conceito foi implementado durante o período de redemocratização do país, relacionando-se à participação e à descentralização da gestão. Nesse caso, o termo vem sendo difundido de forma relativamente uniforme e normativa de acordo com os moldes promovidos por instituições internacionais. Os governos regionais e locais são muito dependentes das decisões tomadas em âmbito federal e as instituições de bacia possuem restrito poder decisório.

Na Suíça, o conceito possui significados e experiências diversas, pois tal abordagem não é exigida pelo governo federal e cada cantão decide seu modelo de gestão de águas. A aplicação da GIRH refere-se sobretudo à coordenação de determinados usos de água durante a realização de projetos. 0 principal desafio para a gestão de águas do país é a fragmentação do sistema, bem como a dificuldade de visão geral.

\section{REFERÊNCIAS BIBLIOGRÁFICAS}

Arretche, M. Why is Brazil a case of demos-enabling federalism? Panoramas. 2015. Recuperado em 10 março 2020, de https://www.panoramas.pitt.edu/news-and-politics/why-brazil-case-demos-enabling-federalism

Aschwanden, H., Pfaundler, M., \& Vollenweider, S. (2008). Gestion des eaux en Suisse 2007: Situation actuelle et thèses. Berne: OFEV.

Balsiger, J., \& Menzel, S. (2012). Auf dem Weg zu einer integrierteren Wasserpolitik in der Schweiz: Kantonale Koordinationsformen und - mechanismen. Teilbericht zum Arbeitspaket 2.1 des Projekts IWAGO - Integrated Water Governance with Adaptive Capacity in Switzerland. Zürich, Dübendorf: Eidgenössische Technische Hochschule Zürich, Eawag.

Banco Mundial. (2003). Estratégias de gerenciamento de recursos hídricos: áreas de cooperação com o Banco Mundial. Série água Brasil. Brasília: Banco Mundial.

Barraque, B. (2007). Les Agences de l'eau et le contexte de la régionalisation. Responsabilité \& Environnement, 46, 73-80.

Bieusses, P. S. (2008). Un État unitaire ultra-fédéral. Pouvoirs, (124), 19-34. 
Biswas, A. (2004). Integrated water resources management: a reassessment. A water forum contribution. Water International, 29(2), 248-256.

Bizberg, I. (2015). Variedades del capitalismo en América Latina: Los casos de México, Brasil, Argentina y Chile. México: El Colegio de México.

Brasil. (1997, 9 de janeiro). Lei n 9.433, de 8 de janeiro de 1997. Institui a Política Nacional de Recursos Hídricos, cria o Sistema Nacional de Gerenciamento de Recursos Hídricos, regulamenta o inciso XIX do art. 21 da Constituição Federal, e altera o art. 1ํ da Lei no 8.001, de 13 de março de 1990, que modificou a Lei no 7.990, de 28 de dezembro de 1989. Diário Oficial [da] República Federativa do Brasil, Brasília. Recuperado em 10 de outubro de 2019, de http://www2.camara.leg.br/legin/fed/lei/1997/lei-9433-8-janeiro-1997374778-norma-pl.html.

Briant, V., \& Briant, V. (2009). Contribution à l'étude des “arrangements fédératifs", de l'État fédéral à l'État unitaire décentralisé "arrangements fédératifs", de l'État fédéral à l'État unitaire décentralisé. Fédéralisme Régionalisme, 9(2), 1-10.

Buchs, A. (2010). Water crisis and water scarcity as social constructions: the case of water use in Almeria (Andalusia, Spain). Options Méditerranéennes, 95, 207-211.

Buchs, A. (2016). Processus de qualification et construction d'un compromis institutionnel territorialisé. La gestion intégrée de l'eau par bassin dans le canton de Fribourg (Suisse). Développement Durable \& Territoires, $7(3)$.

Buchs, A. (2018). Integrated water resources management as a compromise: Renewing the water act in the canton of Fribourg, Switzerland. In C. Bréthaut \& R. Schweizer (Orgs.), A Critical Approach to International Water Management Trends (pp. 45-69). Londres: Palgrave Macmillan.

Carmo, E. (2019). Federalismo e políticas públicas educacionais. Espaço público, 3, 117-136.

Cenicacelaya, M. N. (2014). Los recursos hídricos interprovinciales y el federalismo argentino. In Anais do Congreso Internacional de Códigos y Desafíos para Enfrentar la Crisis del Água, Buenos Aires. Recuperado em 2019 de outubro de 10, de http://hdl.handle.net/10915/43469.

Comité de Direction Du PNR 61. (2015) Gestion durable de l'eau en Suisse: Le PNR 61 montre les voies à suivre pour l'avenir. Synthèse globale dans le cadre du Programme national de recherche. Berne: PNR 61.

Croisat, M. (2010). Le fédéralisme en Europe. Paris: Montchrestien.

Dardanelli, P. (2010). Federal democracy in Switzerland (Routledge Series in Federal Studies). London: Routledge.

De Stefano, L., \& Garrick, D. E. (2018). Governing water in federal river basins. Regional Environmental Change, 18, 1573-1578. http://dx.doi.org/10.1007/s10113-018-1383-x

Empinotti, V. L., Gontijo, W. C., \& Oliveira, V. E. (2018). Federalism, water, and (de)centralization in Brazil: the case of the São Francisco River water diversion. Regional Environmental Change, 18, 1655-1666. http://dx.doi.org/10.1007/s10113-018-1371-1

Espinosa, M. H. A. (2015). La privatización del agua: impacto de las concessiones de agua em Texcoco, estado de México, México. Revista Científica CODEX, 1(1), 91-105. Recuperado em 10 março 2020, de https://revistas.udenar.edu.co/index.php/codex/article/view/2547

Garrick, H., \& O'Donnell, E. (2018). Water markets in federal countries: comparing coordination institutions in Australia, Spain and the Western USA. Regional Environmental Change, 18, 1593-1606. http://dx.doi.org/10.1007/s10113-018-1320-z

Gontijo, W. C., \& Trigo, A. J. (2013). Domínio das águas no Brasil e a gestão integrada por bacia hidrográfica: reflexões sobre o modelo vigente no Brasil. In Anais do IV Encontro Internacional da Governança da Água (pp. 98-108). São Paulo.

Graefe, 0. (2011). River basins as new environmental regions? The depolitization of water management. Procedia: Social and Behavioral Sciences, 14, 24-27.

Grau, M. (2000). Spain: incomplete federalism. In U. Wachendorfer-Schmidt, Federalism and Political Performance (pp. 58-78). London: Routledge/ECPR.

Global Water Partnership - GWP. (2000). La gestion intégrée des ressources en eau. Partenariat mondial pour l'eau (Report No. 4). Stockholm: Global Water Partnership. Recuperado em 10 de abril de 2017, de https://www.gwp.org/globalassets/global/toolbox/publications/background-papers/04-integratedwater-resources-management-2000-french.pdf 
Global Water Partnership - GWP. (2005). IWRM ToolBox Version 2 - Foreword. Global Water Partnership. Stockholm: Global Water Partnership. Recuperado em 10 de março de 2016, de https://sswm.info/sites/default/files/reference_attachments/GWP\%202008\%20IWRM\%20Toolbox\%20V ersion\%202.pdf

Laigneau, P., Formiga-Johnsson, R., \& Barraque, B. (2018). Les agences de l'eau au Brésil et en France: les défis d'une gestion de l'eau en tant que bien commun à l'échelle des bassins versants. Annales de Mines Responsabilités et Environnement, 4(92), 50-54.

Libânio, P. A. C. (2014). The use of goal-oriented strategies in the building of water governance in Brazil. Water International, 39(4), 401-416.

Libânio, P. A. C. (2018). Two decades of Brazil's participatory model for water resources management: from enthusiasm to frustration. Water International, 43(4), 494-511.

Liziero, L. B. S., \& Carvalho, F. (2018). Federalismo e centralização no Brasil: contrastes na construção da Federação Brasileira. Revista de Direito à Cidade. 10(3), 12-31. http://dx.doi.org/10.12957/rdc.2018.32661.

Milano, M., Chevre, N., \& Reynard, E. (2018). Assessing watercourse quality: challenges in implementing European and Swiss legal frameworks. Environmental Science and Pollution Research International, 25(1), 805-823.

Milano, M., Reynard, E., Bosshard, N., \& Weingartner, R. (2015). Simulating future trends in hydrological regimes in Western Switzerland. Journal of Hydrology: Regional Studies, 4, 748-761.

Miranda, G. M. (2013). Gestion intégrée des ressources en eau dans le bassin versant Mèbre-Sorge (Rapport de Stage de Recherche). Lausanne: Université de Lausanne.

Miranda, G. M. (2017). Gestion intégreée des ressources en eau dans les pays fédéraux: les cas suisse et brésilien (tese). Université de Lausanne, Lausanne.

Moreno, L. (1997). La federalización de España: poder politico y territorio (1. ed.). Madrid: Siglo Veintiuno de España Editores.

Musy, A., Higy, C., \& Reynard, E. (2014). Hydrologie 1: Une science de la nature. Une gestion sociétale. Lausanne: Presses Polytechniques et Universitaires Romandes (PPUR).

Palacios, D. S. (2012). El convenio de Albufeira y el plan de cuenca del Tajo. Que implicaciones para el trasvase Tajo-Segura?. In Anais do VIII Congreso Ibérico sobre Gestión y Planificación del Agua (pp. 556-564). Lisboa: Fundación Nueva Cultura del Agua. Recuperado em 10 de outubro de 2019, de http://revistas.lis.ulusiada.pt/index.php/8cigpa/article/download/354/pdf_36

Pearse, P. H., \& Quinn, F. (2013). Recent developments in federal water policy: one step forward, two steps back. Revue Canadienne des Ressources Hydriques, 21(4), 329-34.

Office Fédéral de L'environnement - OFEV. (2012) Gestion par bassin versant: guide pratique pour une gestion intégrée des eaux en Suisse. Ittigen, Suisse: OFEV. Recuperado em 10 de outubro de 2019, de http://www.bafu.admin.ch/publikationen/publikation/01652/index.html?lang=fr

Office Fédéral de L'environnement - OFEV. (2013) Coordination des activités de gestion des eaux: coordination intra- et intersectorielle, multi-niveaux et à l'échelle du bassin versant. Berne: Office fédéral de l'environnement.

Organisation for Economic Co-operation and Development - OECD. (2012) Water governance in Latin America and the Caribbean: a multi-level approach. Paris: OECD. Recuperado em 20 de maio de 2019, de http://www.oecd.org/cfe/regional-policy/watergovernanceinlatinamericaandthecaribbeanamultilevelapproach.htm

Organisation for Economic Co-operation and Development - OECD. (2019) Water governance in Argentina Paris: OECD. Recuperado em 06 de maio de 2020, de https://www.oecd-ilibrary.org/sites/bc9ccbf6en/index.html?itemId=/content/publication/bc9ccbf6-en

Petry, D., \& Dombrowsky, I. (2007). River Basin Management in Germany: Past Experiences and Challenges Ahead. In J. D. Erickson, F. Messner, \& I. Ring (Orgs.), Ecological Economics of Sustainable Watershed Management (pp. 11-42). Bingley: Emerald Group Publishing Limited.

Posner, G. (2014) Le fédéralisme, recette pour une démocratie efficace. Recuperado em 20 de setembro de 2019, de http://www.taurillon.org/6286.

Remon, M. (2018). Le partage de l'eau: une réflexion géopolitique. Revue Projet, 367(6), 94-94. http://dx.doi.org/10.3917/pro.367.0095 
Reynard, E. (2000). Gestion patrimoniale et intégrée des ressources en eau dans les stations touristiques de montagne: les cas de Crans-Montana-Aminona et Nendaz (Valais) (Tese de doutorado). Université de Lausanne, Lausanne.

Riker, W. H. (2017). Federalism. In R. E. Goodin, P. Pettit, \& Pogge, T. A Companion to Contemporary Political Philosophy (pp. 612-620). New York: Wiley Online Library. http://dx.doi.org/10.1002/9781405177245.

Robertson, D. B. (2018). Federalism and the making of America (2. ed.). New York: Routledge.

Rovere, M. (2006). Argentina. In, A. Iza, \& M. B. Rovere (Orgs.), Gobernanza del agua en América del Sur: dimensión ambiental. Cambridge: Económica y Desarrollo, Unión Mundial para la Naturaleza.

Saint-Ouen, F. Le fédéralisme. Paris: Infolio Éditions, 2005.

Sandoval-Solis, S. (2019). Water Resources Management in California. In E. Vieira, S. Sandoval-Solis, V. Pedrosa, \& Ortiz-Partida, J. (Orgs.), Integrated Water Resource Management. Springer, Cham.

Scantimburgo, A. L. (2013). O Banco Mundial e a política nacional de recursos hídricos. São Paulo: Cultura Acadêmica.

Schrubsole, D., Walters, D., Veale, B., \& Mitchell, B. (2016). Integrated Water Resources Management in Canada: the experience of watershed agencies. International Journal of Water Resources Development, 33(3), 349. 359.

Soares, M. M., \& Machado, J. A. (2018). Federalismo e políticas públicas. Brasília: ENAP.

Trein, P., \& Braun, D. (2016). How do fiscally decentralized federations fare in times of crisis? Insights from Switzerland. Regional \& Federal Studies, 26(2), 199-220.

Trillo, F. H. (2015). Federalismo ambiental em America Latina: uma revisión. Santiago de Chile: Naciones Unidas, Cepal, Union Europea. Recuperado em 18 de março de 2020, de https://repositorio.cepal.org/handle/11362/39661

Utz, C., \& Reynard, E. (2017). Processus participatifs et projets d'aménagement des cours d'eau. Analyse de l'implication des acteurs dans la planification du projet de 3ème correction du Rhône suisse entre 2000 et 2015. Géocarrefour, 91(4), 1-20.

Villada-Canela, M., Martinez-Segura, N., \& Mendoza-Espinosa, L. (2019). Fundamentals, obstacles and challenges of public participation in water Management in Mexico. IMTA-TC, 10, 12-46.

Visscher, C., \& Laborderie, V. (2013). Belgique: stop ou encore? Entre fédéralisme, confédéralisme et séparatisme. Politique Etrangere, 4, 3-35.

White, G. F. (1998). Reflections on the 50-year international search for integrated water management. Water Policy, 1, 21-27.

World Bank (1999). Management of water resources: bulk water princing in Brazil. Washington: World Bank.

World Bank (2000). Argentina Water Resources Management Policy Elements for Sustainable Development in the XXI Century. Main report. Washington: World Bank.

World Bank (2019). World development indicators. Recuperado em 18 de março de 2020, de https://databank.worldbank.org/reports.aspx?source=2\&series=SI.POV.GINI\&country. 